\title{
Teachers' Attitudes towards Lesson Study as a Viable Strategy to Improve the Teaching and Learning of Mathematics
}

\author{
Simon Adjei Tachie \\ Faculty of Education, School of Mathematics Natural Science and Technology Education, University of the Free State (RSA), \\ South Africa
}

Received February 27, 2020; Revised March 30, 2020; Accepted May 13, 2020

Copyright $\odot 2020$ by authors, all rights reserved. Authors agree that this article remains permanently open access under the terms of the Creative Commons Attribution License 4.0 International License

\begin{abstract}
The emphasis on high-quality education and professional development of teachers in order to improve the performance of learners in schools continues to be a topic of discussion worldwide in the $21^{\text {st }}$ century. A series of workshops and programmes are therefore being organized for most of the teachers in South Africa in order to prepare them for quality teaching and learning in schools. However, in the interim, learners' performance in mathematics continues to be unsatisfactory in South Africa when compared to learners in other nations. A qualitative approach was used for this study and the article draws data from participatory action research, with a focus on teachers' attitudes towards lesson study as a viable strategy to improve teaching and learning of mathematics in South African schools. A combination of interviews and observations was used to gather data from thirty-five purposefully-selected teachers who participated, together with thirty learners in a lesson study workshop in one of the Universities in South Africa. The study found that teachers displayed a positive attitude towards lesson study even though they had limited time to engage in daily preparation, hence inadequate performance on the part of their learners. The implications drawn from the researcher's findings were that failure to address teacher professionalism, especially regarding the use of lesson study to improve their methods of teaching mathematics, which is likely to derail all other attempts to address learners' poor performance in mathematics. Participants therefore recommended that lesson study be enforced by the national Department of Education to improve teachers' methods of teaching mathematics in South African schools through innovative approaches.
\end{abstract}

Keywords Lesson Study, Viable Strategy, Attitude to Mathematics, Teaching and Learning, Mathematics

\section{Introduction}

It is important to note that teachers' methods of teaching are considered to play a significant role as far as understanding and performance in mathematics are concerned. To improve the quality of teaching and learning in schools, the outcomes of the current teachers' experiences of teaching and learning of mathematics in schools should inform and influence other teachers' methods of teaching using a lesson-study model. Ni Shuilleabhaina and Seeryb [1] has reported in their findings that lesson study acts as a powerful tool for Professional Development (PD) by way of encouraging new pedagogical practices in the Republic of Ireland Curriculum Reform (RICR).

This is in line with the assertion by Zapalska, Zieser and Kelley [2] and Fujii [3] that teachers in the $21^{\text {st }}$ century should be trained to acquire creative and critical thinking skills that prepare learners for a dynamic future in life in which innovation and creativity in learning will effectively be established.

Involving teachers' professionalism in the lesson study approach helps to introduce them to the lesson-building processes, which, in turn, guide, direct and influence their methods of teaching in the classroom $[1,4]$. To help teachers to develop professionally, they will need to focus on learners' in order to address the teaching of specific curriculum content for their learners' psycho-social development; thus, they need to build a link between teaching and learners' mastery of mathematical concepts. This means that teachers should always reflect on their teaching and learning to assess what went wrong, what can be explored further, how to explore and what can be done to improve their professionalism. This is a form of lesson study. According to Fernandez and Chokshi, cited in Burroughs and Luebeck [4], "lesson study is a process 
for creating deep and grounded reflection about the complex activities of teaching that can be shared and discussed with other members of the profession." Teaching involves individuals changing lives. Teachers should assist or develop learners to their full potential academically, socially and emotionally, so they need to set up teaching and learning situations in a special way that encourages learners to do their own thinking in learning situations. In other words, they should not be "spoon feeders" of information. Instead, they need to create a conducive environment that supports learners' creativity through self-exploration in solving life's problems.

South Africa is one of the countries in Africa that usually takes part in TIMSS assessment with dismal performance among its learners in Mathematics and Science. Studies have shown that lesson study has not been popular in South Africa in order to guide teachers in the planning of their lessons; hence scholars may attribute learners' poor performance to this shortcoming [5]. It has therefore become imperative for the researchers and academics to engage both pre-service and post-service teachers in intensive lesson study models to equip teachers with relevant skills and strategies in order to assist learners in mathematics problem solving in South African schools. Teachers in this study collaboratively prepared lesson studies under the supervision of certain lecturers who were part of the project at the selected university. The aim was not to focus on how much teachers needed to know but how they needed to know, and what else they needed to know in teaching of mathematics through this particular lesson study project. This serves as part of the professional growth of South African teachers, based on Japanese teaching methods.

\section{Problem Statement}

Related studies have identified the fact that many of the professional development projects have not been able to change the classroom practice of the teachers in order to prepare learners for a dynamic future in the $21^{\text {st }}$ century [6]. In the same way, studies on lesson study, as a viable strategy to improve teaching and learning in mathematics classes have been minimal in South Africa [5]. Related literature confirms that in South Africa there is a shortcoming in the way that lesson study is used as a remedy to address the issues of the quality of teachers' professionalism in the country's education system. It is, however, important to know that strides have been made at the international level to demonstrate the importance of the lesson study model to the classroom teacher in professional development efforts. This has been undertaken by sharing ideas and limited resources collaboratively in the teaching of mathematics. This adapted innovative Japanese approach can help pave the way for rural mathematics teachers, through collaboration, to improve their methods of teaching and learning of mathematics in class $[7,8]$. It is therefore important to conduct this study in South Africa where many rural and township schools are disadvantaged and under-performing.

\section{Research Question}

In order to help the researcher to assess the stated problem, the following research question was posed:

In what ways do teachers consider lesson study as a viable strategy to improve their teaching and learning of mathematics in schools?

\section{Theoretical Frameworks}

As stated learners' performance in the study of mathematics has not been encouraging, the problem is mostly attributed to learners' attitude towards the study of the subject and teachers' inability to embark on intensive collaborative lesson study to address their shortcomings in the teaching of mathematics. This study was influenced by two theories, namely, Bandura's [9,10] theory of self-efficacy as well as attitude-behaviour relation's theory $[11,12]$. These theories are presented in this paper to reflect on the relationships, attitudes, efficacy prior to studies investigating the influence of attitude and self-efficacy on teachers' use of lesson study in classroom practice.

Research has shown that many intervention programmes have been undertaken to improve teacher's professionalism worldwide and in South Africa [13,14,15]; for example, in South Africa, Jita, Maree and Ndlalane [16] embarked on a study which focused on an in-service education programme for developing teachers. It was structured along the lines of the Japanese lesson study model. This justified the use of the self-efficacy theoretical framework in the current study since the programme provides elements that are in line with mathematics teacher professionalism. In this regard, Bandura advises that people (in this case, teachers) should try to regulate their behaviour when doing something on the basis of a belief system for development; hence, teachers in this study embarked on the lesson study model in order to develop themselves professionally by sharing ideas and information. This concurs with the view of Jita et al. [16] and Yulianto, Kamidjan and Asteria [17] who contend that a lesson study approach, as a component of curriculum implementation, establishes a system whereby teachers rely on one another in coaching, leading interactive discussions and exploring alternative ways of solving mathematics problems in class. This lesson study approach was carried out as a professional way of planning by way of a positive through a positive attitude, dedication and commitment as a group with one common idea. According to Bandura [10], people mostly regulate their behaviour of doing something on the basis of a belief 
system, particularly beliefs of personal efficacy (the power to produce desired outcomes out of a commitment and to forestall undesired ones) and self-efficacy (the belief in one's own ability to execute a certain course of behaviour successfully to achieve a goal). Both of these efficacy forms are considered to be situations or task-specific key factors in how people construct and live their lives in order to achieve something in life. The current generation has experienced changes in mathematics education, and teachers are expected to use new teaching approaches in their classroom teaching and learning such as enquiry-based teaching, open approach-based teaching, the lesson study model and so on [18].

Teachers' use of lesson study in mathematics classrooms should ultimately be such that it influences the lives of the learners in the learning of mathematics. It therefore ought to make teaching and learning more practical and understandable since most of the key concepts have been discussed collaboratively and been well explained during the lesson study session among the participating teachers. This helps to make the learning of mathematics more enjoyable for learners when their teachers present understandable and practical lessons rather than abstract presentations in which teachers merely have the knowledge of the content and teaching aspect.

\section{Context of the Study}

The primary objective of this study was to investigate teachers' attitudes towards lesson study as a valid strategy to improve teaching/learning of mathematics in schools, based on their understanding of lesson study, the way they felt about it and how they participated as a way of developing themselves professionally when being innovative during the lesson. In this study, the researcher played many roles to ensure that valid and important data were collected and analysed in order to understand the context of the data-collection procedures (designed for this particular study) to improve the performance of mathematics teachers in the Free State Province. The researcher, therefore, became a participant observer whereby every stage of the research (that is, lesson study group discussion) was observed and monitored closely by the lesson study professionals in order to gather relevant information. As stated, the study took place at one of the Universities in the country. It targeted only Senior Phase (Grades 7-9) mathematics teachers from certain rural schools. The idea of the innovative approach to lesson study was introduced to participants by a group of mathematics and science lecturers who were part of a research team on teacher's professional development through the lesson study model in the province. Teachers in this study subjected themselves to routine activities similar to Japanese teachers. The participating teachers in each group were also given opportunities to provide feedback on how to improve on their lesson plans for the final stage which one participating teacher concerned had to present. The focus was not only on content knowledge but on how to assist learners to learn mathematics effectively in class; the presentations, therefore, dealt not only with how much teachers needed to know about lesson study but how they needed to know and what else they needed in the teaching of mathematics by considering the experiences of the lesson study. This was an adapted form of the Japanese lesson study in which it looked at the procedures followed, based on the objectives of the lesson $[3,18]$.

Teachers in Japanese schools, more often than not, attribute much of their professional growth and effective performance to the practice of "jugyokenkyuu", translated as lesson study $[17,19,20]$. The participating teachers in this study therefore engaged in constructive discussions of lesson plans which resulted in developing the means of creating models or objects in order to solve mathematics problems through complex processes under the supervision of the mathematics lecturers in the research group. These activities were carried out in a cyclical manner. This particular lesson study model of developing teachers is mostly used systematically to direct the focus of the teachers' content knowledge and teaching in order to increase their understanding of the pedagogy of teaching mathematics. Moreover, it helps to develop the teachers' ability to observe the behaviour of their learners in the learning process in order to understand the link between mathematics teaching and learner learning [21,22]. Figure 1 is an illustration of the lesson study model used by the participants in this study: 


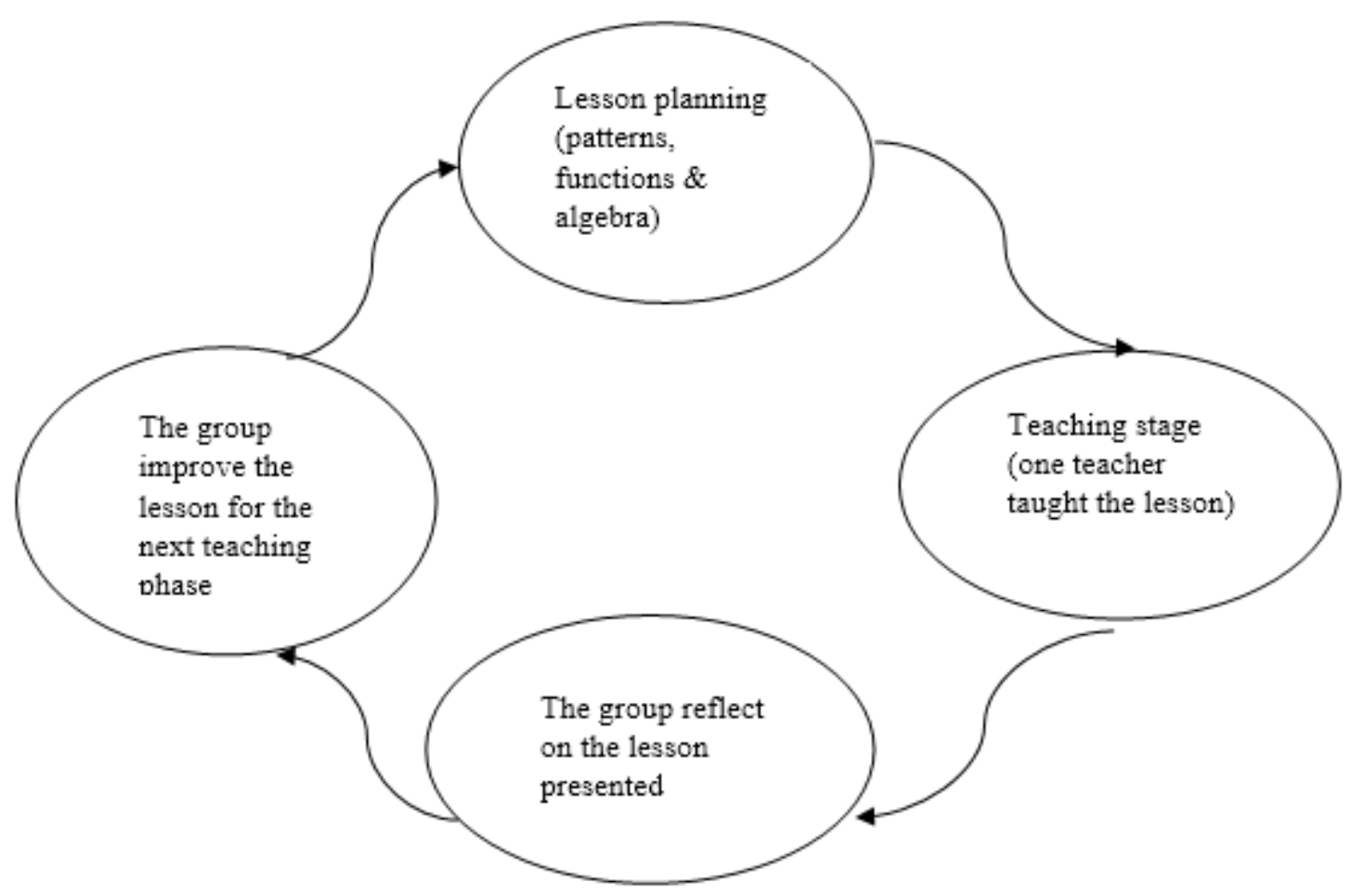

Figure 1. Lesson study illustration for the purpose of this study

\section{Research Methodology}

\subsection{Design}

The case in this paper relates to the need for the participants to understand, in-depth, the experiences of lesson study as a viable strategy to improve teaching and learning of mathematics in the Free State Province by building a link between teaching and learners' learning of mathematics. This therefore warranted the involvement of other stakeholders such as mathematics and science lecturers, certain selected rural and township schoolteachers as well as some learners from purposely-selected schools in the province. All the participants met at the selected University for the study. Consideration of teachers' behaviour and abilities to improve their methods of teaching of mathematics in schools was based on classroom observation and participation in the collaborative lesson study group project as a criterion for inclusion of target groups. The study involved a qualitative action research study of an exploratory nature. The participants comprised thirty Grade 7 learners, aged 12-15, and thirty-five mathematics teachers teaching Grades 7-9 in various schools falling under the Free State Department of Education. The purposely-selected participants thus worked as a team comprising six to eight teachers in a team in order to share ideas and experiences for the betterment of teaching and learning of mathematics in schools. Many activities were engaged in for this study to be successful.

\subsection{Data Generation}

A combination of observation and interviews was used to gather data from the above teachers and learners in a lesson study workshop at the selected University. The participants were involved in collaborative lesson planning and presentation as a way of sharing ideas and information together in regulating their teaching with a view to the development of professionalism in the teaching of mathematics in schools [10]. The idea was to establish how teachers viewed lesson study as the activities were unfolding during their collaborative engagement, as a way of improving and refining lessons prepared by individual groups. The obvious intention was also to improve their professional way of teaching mathematics, rather than using the traditional approach, by interacting with one another in exploring alternative ways of teaching mathematics. Many activities were observed that culminated in the critical analysis of the study on the basis of the personal efficacy belief system emanating from commitment.

The participating teachers, in collaboration with the mathematics lectures, duly designed the series of lessons presented to the learners. The participating teachers then proceeded to revise the lessons where possible in order to make this study a success. The activities given to learners during lesson presentations were also checked to ascertain whether or not new concepts were displayed in order to pave the way for learners in problem solving. The concepts and ideas previously learned were checked and used as a foundation on which to create new mathematical 
knowledge for the learners' advantage. The research team planned and worked collaboratively with the participating teachers, as directed by the project coordinator, in considering determining attributes of the target group, based on the following criteria, which incorporated, what Suriyon, Inprasitha and Sangaroon [23] established:

- How teachers presented their lessons coupled with learners' ability to respond positively, ability to think outside the box, explanations of their own thinking and that of the group, making use of teaching/learning materials and available resources.

- Teachers' behaviour when monitoring learners, concentration on one particular direction or diverse ways of responding to learners' questions differently and collaboratively.

- How teachers used illustrations to explain their points or a particular problem at hand.

- Teachers' ability to monitor their own thinking through trial and error.

- Ability to challenge a point in a certain situation.

- Ability to reflect on their (teachers') teaching and learning in order to produce a quality or successful outcome.

All the above were monitored to ascertain professional development and ways of teaching mathematics for the learners' benefit. All the participating teachers who were monitored were both mathematics and science teachers. However, for the purpose of this study, the concentration was on the teaching of mathematics in class. Throughout the days of collaborative lesson study engagement, the participating teachers were given opportunities to plan, observe, critique and reflect on their teaching activities. All elements of engagement were video-taped and reported together with other data for this study.

Self-efficacy as well as attitude-behaviour theory, which was used in this study, concerned individuals' intentions and attitudes to use the lesson study idea for effective teaching of mathematics in schools. It involved teachers building a link between teaching and learners' learning; in other words, how teachers efficiently share ideas through collaborative discussion on knowledge of the content and teaching, and to use the shared ideas to teach mathematics for learners' better understanding. The aim of using the lesson study model in mathematics classrooms in this study was, therefore, basically to merge the best of the individual classroom teaching approaches or ideas with face-to-face teaching or to take into account the best of the various approaches which evolved during collaborative lesson discussion. In this study, an individual's perception of his/her ability to competently apply the skills and experiences of the collaborative lesson study model featured in his/her teaching is defined as lesson study self-efficacy.

\subsection{Class Observation}

The classroom observations in this study were undertaken before, during and after the intervention, with at least one observation made of each teacher (the presenter) in the class where the study took place. The observations during and after the intervention were carried out with the aim of measuring teachers' shared opinions and experiences, as well as their intensions and attitudes towards the use of lesson study ideas for the betterment of teaching and learning of mathematics in schools, as supported by Bandura. In addition, it was important to establish how teachers viewed lesson study as a viable strategy to improve teaching and learning of mathematics through the activities which are unfolded during their collaborative engagement and as a way of improving and refining their lessons prepared by individual groups.

\subsection{Data Analysis}

Creswell's [24] qualitative data analysis was considered in analyzing the data gathered from the collaborative lesson-study cycle. During analysis, the data collected were transcribed to develop relevant categories and themes. The researcher therefore ascertained how teachers were able to use collaborative lesson study effectively to develop new pedagogical practices through reflection of teachers' self-efficacy of teaching mathematics deemed to help learners in solving mathematics problems logically. The researcher further characterized the main ideas generated during reflection of the lesson study as well as learners' ideas generated during the process of problem solving as a result of the lesson study model and how it helped learners to understand the problem or concept easily. The focus was also on how learners assessed the potential use and weakness of information or ideas to solve a problem based on the interventions made by the participating teachers $[4,22]$. Responses from the participants were then analysed. One had to check whether the teachers had knowledge of both the content and teaching; in other words, how they presented a concept to the learners during this project. Triangulation of different data sources was used as a way of addressing the validity of the study. The research team actually directed the program as encapsulated in the prescript of the mother project that supported the participating teachers' engagement in the lesson-study model. The paragraph below presents the results obtained from the data analysis.

\section{Results and Discussion}

The results of the paper are presented based on the categories and themes that emerged from the coding and analysis pertaining to the data obtained from the participants during the development of the sequence (planning, observation, learners' activities and interviews), together with a brief argumentation for the categorisation. 


\section{Class Observation}

During classroom observations, the focus was mainly on the way teachers presented their lessons in relation to their content knowledge as a way of verifying their self-efficacy of teaching mathematics based on their attitudes towards lesson study. Observations in this study were carried out before, during and after the intervention, with at least one observation made of each teacher (the presenter) and the learners. The observations during and after the intervention were carried out with the aim of measuring teachers' shared ideas and experiences for the betterment of teaching and learning of mathematics in schools. Furthermore, the group reflected on the presenter's lesson to determine from him/her what he/she actually found to have done well during a particular lesson presentation, what went wrong or did not go well, and what could be done to address the areas of weakness or problems if necessary. This is aligned with the judgment of what can be done through experience so as to inform modifications to the lesson-study model in future for the benefit of both the teachers and learners globally. It refers to judgments of ability to apply lesson-study skills from problem-solving situations to broader tasks such as promoting education and professionalism among teachers. In this regard, lesson study self-efficacy does not refer to component skills such as listing or mentioning specific lesson-study features, but rather the ability to apply such skills or features to convey mathematical meanings to one's learners when teaching mathematics in the classroom. Bandura [9] emphasises the importance of self-perception and efficacy as cognitive mediators of action. The estimate of a teacher's own ability and application was important in this study. The theory states that whether or not a person undertakes a task depends, in part, on his or her perceived level of efficacy regarding that task. In this case, it revolved around how teachers could effectively use the lesson study model to teach mathematics in schools based on prior knowledge of using individual teaching approaches, hence the use of this model in this study.

Ni Shuilleabhaina and Seery [1], Posthuma [5], Dogan et al. [7] and Ni Shuilleabhain [25] believe that observing a collaborative lesson presentation and reflection usually paves the way for teachers to incorporate and develop new pedagogical practices by shifting their thinking from a teaching focus to a learning focus whilst puzzling over their learners' mathematical thinking. As prospective observers, teachers need to focus their attention on learners' progress by checking on the activities that learners are doing during the lesson as well as learners' thought processes in developing their cognitive abilities to solve world problems. During the reflective process, some observers responded to certain issues according to their respective observations that obstructed them during the lesson delivery; for example, in response to an open interview question as to why they agreed to partake in this project. In their responses, two teachers coincidentally said:

We could not have come here if not because of our principals because normally we not have time to plan our lessons due to overloaded activities in the school. We only take our books and go to class. But now, our coming here is not in vain. We have gained a lot in this project. This could be because of the positive results acquired or the influence of the standard of good lesson planning in this project. Another teacher admitted: Now my learners can get a direction of learning mathematics because I have now acquired the skill of tracing their mistakes and how to set good objective(s) and achieve it due to the ways this lesson study implementation was done.

\section{Experience in the Lesson Study Model}

The purposely-selected participating teachers spent a few hours working collaboratively as a team comprising six to eight teachers in a group in order to share ideas and experiences through planning, teaching, reflection, revision and re-teaching for the betterment of teaching and learning of mathematics in schools [22]. The teachers in this study had different teaching experiences and were relatively new to lesson study; they also had a limited relationship with each other as well as the learners. Based on the broad aim of the project, the participating teachers also identified an area of difficulty in mathematics. With this in mind, they began as a group to develop the broad aim and thus planned lessons towards achieving a particular goal in the teaching and learning of mathematics. Participants were initially given a lesson study template to observe and this allowed them the opportunities to make observations, reflect and make suggestions before the commencement of the actual lesson preparation and at the reflection stage of the presented lesson. They therefore planned their lessons (interventions) using learners' responses by observing the errors, mistakes and misconceptions they (learners) often experienced during teaching and learning and assessment. The group met to collaborate and plan their first lesson, and the subsequent lessons were refined by individual groups and presented by individual teachers in each group. What transpired during the study was that one participant teacher in one particular group taught the carefully planned lesson while the others observed in order to get the real picture of the lesson and its effectiveness for the betterment of their learners. After the presentation, the group met and constructively critiqued the teacher who presented the lesson, revised the lesson taught (based on their data gathered) and re-taught the refined lesson where necessary $[4,19]$. During the course of the presentations, the groups' revised lessons were displayed 
on one end of the chalkboard, together with their aims/objectives, activities to be carried out, assessment criteria, prerequisite knowledge as well as reflection and other related motives to be achieved which at the end of the lesson were critically taken into account by the observers and the researcher. This helped the researcher to gather accurate and trustworthy data during the reflective stage.

\section{Interpretation of Data}

Data were qualitatively collected based on the learners' class activities which, in turn, were based on the lesson study cycle, conference/open reflective sessions about the experiences of lesson-study processes, transcripts of the video-recorded lessons, summary reports of the participating teachers, comments from the audience, learners' comments and individual interviews. The analyses were done to establish whether or not the teachers had reflected on their learners' thinking as well as the understanding of the concepts to be taught in order to prepare for learners' contributions and feedback. Tentatively, some participants presented their individual reflections, however, most of the participants' responses arose out of the group discussions where most of them expressed their emotions, feelings and experiences about lesson study.

The discussion below highlights the following themes that emerged during data analysis: benefits of lesson study, reflection on learners' mathematical knowledge and improvement of their pedagogical content knowledge (PCK).

\section{Benefits of Lesson Study}

The responses given by the respondents after observations made on the lesson study indicated that they had acquired useful experience. This was achieved through reflection on their mathematical knowledge and improvement of their PCK. The following sentiments represented some of the participants' oral responses:

TA: I never knew you could use this lesson study to make teaching and learning of maths so easily like that except today. All along I have been struggling teaching some of the topics in class but through this lesson study, I have now got some skills and strategies of teaching those topics with ease. I can even close my eyes and teach those topics without difficulties. In fact, this lesson study model should be extended to all parts of the province in order to equip mathematics teachers in teaching of mathematics without fear. Some of the teachers have been experiencing problems with the terms or concepts to be taught.

TK: In actual fact I thought at the beginning that I have been embarrassed because of the way they were criticising my mistakes, making a lots of comments about my teaching. Some of them even said there were materials there as teaching aids but they did not see me using it in my teaching. I felt so uncomfortable initially but after the criticisms from the floor, I later realised that I have learnt a lot of things from them. I have realised my mistakes which I belief will not help learners if I had taught that lesson in class. I even cried they criticised me but I feel released because now I am very confident that if I should teach this lesson again, I will make them feel small. This means that as teachers, we need to always emback on these lesson study activities that will help us in our teaching and learning.

\section{Implications of the Study}

\subsection{Improvement of Pedagogical Content Knowledge}

Teachers indicated that their pedagogical knowledge of teaching mathematics had improved through lesson study even though they had challenges initially in adjusting to the lesson study environment. The responses from participants indicated that they initially planned their lessons haphazardly without taking into consideration the prior knowledge of the learners; by ignoring prior knowledge and reflective activities it made learners understand mathematics very difficult and their misconceptions raised to another level. The study also revealed that during lesson study collaboration, the teachers developed new ways of building on their learners' prior knowledge in the teaching of mathematics. They realized how much they needed to know and what else they needed to know in teaching of mathematics. The findings of the study, as indicated by the participants in this study, concur with the findings of Lewis [19] who found that usually lessons planned in the collative lesson study context had a significant impact on teachers' individual professionalism and their views of learners, and how they contributed to their learner's growth or progress. In addition to this, Ni Shuilleabhaina and Seery [1] and Posthuma [5] confirm that collaborative lesson planning helps to anticipate learners' response in learning. It also helps in improving teacher professional development and evaluating questions for observers who observe the public teaching. Discussing and reflecting on the observations are also beneficial to the way teachers respond to their reflective practice. Through lesson study, new skills, strategies, content knowledge and approaches are acquired, emerging competitive views of dissemination of information are shared and the demand for improvement is created.

All these imply that with key concepts in mind in planning of lessons, provisions should be made for learners to reflect on their mathematical knowledge in order to develop their cognitive abilities in the mathematics class. Moreover, the study revealed that through implementation of a good lesson plan, teachers were able to trace learners' learning mistakes which are usually committed when 
solving problems. These can be traced and responded to at an appropriate time or even instantly for learners' development now and in the future, and help the teacher in planning and choosing resources. To this end, the teachers indicated that lesson study had the potential to achieve objectives and transform teaching and learning of mathematics for the better in mathematics classes.

Failure to address teacher professionalism, especially regarding the use of lesson study to improve their methods of teaching mathematics, can derail all other attempts to address leaners' poor performance in mathematics. Participants therefore recommended that lesson study be enforced by the Department of Education to improve teachers' method(s) of teaching mathematics in South African schools through innovative approaches such as reflection on leaners' mathematical content knowledge, and the introduction of different types of activities in the classroom which they considered to be sufficient and useful in assisting in developing their learners to apply certain concepts to other areas of study as well.

\section{REFERENCES}

[1] Ni Shuilleabhaina, A., Seeryb, A. Enhancing Curriculum reform through lesson study: a case study of mathematics teacher learning, Professional development in education, Vol.44, No.2, 222-236, 2018.

[2] Zapalska, AM., Zieser, N., Kelley, T. Strategies for self-leadership development: An example of the U.S. Coast Guard Academy, International Journal of Business and Public Administration, Vol.12, No.2, 66-75, 2015.

[3] Fujii, T. Implementing Japanese lesson study in foreign countries: misconceptions revealed, Mathematics teacher education and development, Vol.16, No.1, 65-83, 2014.

[4] Burroughs, E.A., Luebeck, J.L. Pre-service teachers in mathematics lesson study, The Mathematics Enthusiast, Vol.7, No.2, 391-400, 2010.

[5] Posthuma, B. Mathematics teachers' reflective practice within the context of adapted lesson study, Pythagoras, Vol.33, No.3, 1-9, 2012

[6] Zapalska, AM., Zieser, N., Kelley, T. Management in firms and organizations Leadership development in undergraduate programs: an example at the U.S. Coast Guard Academy, Problem and Perspectives in Management, Vol.14, No.1, 30-43, 2016.

[7] Dogan, S., Pringle, R., Mesa, J. The impacts of professional learning communities on science teachers' knowledge, practice and student learning: a review, Professional development in education, Vol.42, No.4, 569-588, 2016.

[8] Myers, J. Lesson study as a means for facilitating preservice teacher reflectivity, International Journal for the Scholarship of Teaching and Learning, Vol.6, No.1, 15, 2012.

[9] Bandura, A. Self-efficacy: The exercise of control, Freeman,
New York: Freeman, 1997.

[10] Bandura, A. Self-efficacy assessment. In R. Fernandez-Ballesteros (Ed.), Encyclopedia of psychological assessment (Vol. 2, pp. 848-853), Sage Publications, London, 2002.

[11] Doll, J., Ajzen, I. Accessibility and stability of predictors in the theory of planned behaviour, Journal of Personality and Social Psychology, Vol.63, No.5, 754-765, 1992.

[12] Glasman, L.R., Albarracin, D. Forming attitudes that predict future behavior: A meta-analysis of the attitude-behavior relation, Psychological bulletin, Vol.132, No.5, 778, 2006.

[13] Jita, L.C., Mokhele, M.L. When teacher clusters work: selected experiences of South African teachers with the cluster approach to professional development. South African Journal of Education, Vol.34, No.2, 1-15, 2014.

[14] Gamble, J. Teacher professionalism: A literature review. JET Educational Services, Johannesburg, 2010.

[15] Webb, P., Austin, P. The family maths programme: parents' perceptions of what influences their engagement, enjoyment and confidence within a complex learning community, Education as Change, Vo.13, No.1, 27-44, 2009.

[16] Jita, L.C., Maree, J.G., Ndlalane, T.C. Lesson study (Jyugyo Kenkyu) from Japan to South Africa: A science and mathematics intervention program for secondary school teachers, In B. Atweh, A.C. Barton, M. Borba, N. Gough, C. Keitel, C. VistroYu, et al. (Eds.), Internationalisation and globalisation in mathematics and science education (pp. 465-486), Springer, Dordrecht, 2006.

[17] Yulianto, B., Kamidjan, A.A., Asteria, P.V. Development of short Indonesian lesson plan to improve teacher performance, IOP Conf. Ser., Mater. Sci. Eng. 296012001 , 2018.

[18] Witterholt, M., Goedhart, M., Suhre, C. The impact of peer collaboration on teachers' practical knowledge, European Journal of Teacher Education, Vol.39, No.1, 126-1243, 2016.

[19] Lewis, C. How does lesson study improve mathematics instruction? ZDM, Vol.48, No.4, 571-580, 2016.

[20] Perry, R., Lewis, C. Teacher-initiated lesson study in a Northern California district. Paper presented at the Annual Meeting of the American Educational Research Association, Chicago, Illinois. (ERIC Document Reproduction Service No. ED478391), 2003.

[21] Murata, A., Takahashi, A. District-level lesson study: How Japanese teachers improve their teaching of elementary mathematics. Paper presented at a research pre-session of the annual meeting of the National Council of Teachers of Mathematics, Las Vegas, NV, USA, 2002.

[22] Lewis, C., Perry, R., Hurd, J. Improving mathematics instruction through lesson study: a theoretical model and North American case, Journal of mathematics teacher education, Vol.12, No.4, 285-304, 2009.

[23] Suriyon, A., Inprasitha, M., Sangaroon, K. Students' Metacognitive Strategies in the Mathematics Classroom Using Open Approach, Psychology, Vol.4, No.07, 585, 2013. 
[24] Creswell, J.D. Research design: Qualitative, quantitative and mixed methods approaches, (2nd edn.), Sage Publications, Thousand Oaks, CA, 2003.

[25] Ni Shuilleabhain, A. Developing mathematics teachers' pedagogical content knowledge in lesson study: case study findings, International journal for lesson and learning studies, Vol.5, No.3, 212-226, 2016. 